\title{
CENNING RARA: MANTRA DAN DOA MASYARAKAT BUGIS
}

\author{
Hasnitasari \\ Program Studi Bahasa dan Sastra Indonesia, Fakultas Sastra \\ Universitas Muslim Indonesia \\ hasnitasariri@gmail.com
}

\begin{abstract}
Abstrak
Kata Cenning rara biasa diartikan oleh masyarakat Bugis di Sulawesi Selatan sebagai "wajah manis". Kata 'cenning' memiliki arti manis di mana dalam pengertian masyarakat Bugis, yaitu wajah yang terlihat manis dan menarik. Doa yang digunakan tentu memiliki makna yang terkait pada hubungan cinta dan kasih sayang. Bacaan mantra Cenning rara diwariskan oleh leluhur Suku Bugis dan Suku Makassar. Meski begitu, kekuatan mantra Cenning rara bisa berbeda-beda pada setiap orang, baik pengguna maupun objek/sasaran mantranya. Sebabnya, cara kerja mantra yang hendak masuk pada ranah psikis seseorang, jiwa mengenalinya sebagai getaran asing. Maka, yang dilakukan psikis seseorang pun sama dengan tubuh. Yakni menolak dan melawannya. Jika psikis seseorang kuat, pengaruh mantra dapat ditolak untuk kemudian digagalkan. Namun, jika psikis orang itu lemah, akan terjadi hal sebaliknya, ia akan menerima tujuan mantra Cenning rara.
\end{abstract}

Kata Kunci: Cenning rara, mantra dan doa, masyarakat Bugis

\section{PENDAHULUAN}

Antropolinguistik merupakan ilmu yang menggabungkan antara unsur bahasa dan kebuayaan. Ilmu ini meneliti mengenai sejauh mana pengaruh budaya dalam ragam bahasa yang timbul, serta menggkaji antara dan kebudayaan mempunyai keterkaitan yang amat erat, keterkaitan tersebut menurut para ahli adalah: bahasa sebagai alat atau sarana kebudayaan, bahasa sebagai bagian kebudayaan, bahasa merupakan hasil kebudayaan, bahasa hanya mempunyai makna dalam latar kebudayaan yang menjadi wadahnya.

Cenning rara sebagai mantra warisan leluhur Sulawesi Selatan merupakan wujud ideal dari kebudayaan. Sifatnya abstrak, tidak dapat diraba dan dilihat dengan mata kepala. Lokasinya tersimpan di ingatan atau dengan kata lain, dalam alam pikiran masyarakat tempat kebudayaan bersangkutan itu hidup.
Cenning rara yang merupakan contoh dari hubungan budaya dengan bahasa, sebuah cara yang biasa ditempuh para gadis/laki-laki sejak lampau di tanah bugis untuk memikat hati seseorang yang disukai. Mencari pasangan hidup memang bukan perkara mudah. Kata orang, susahsusah gampang. Beragam taktik dimainkanpun beragam cara dilakukan, untuk menemukan "dia" sang belahan jiwa. Satu di antaranya Cenning rara,

Siapa yang ingin hidup melajang selamanya. Telat jodoh saja sudah membuat kegelisahan luar biasa, tidak saja pada yang bersangkutan tapi juga pada keluarga. Apalagi bagi sang perempuan, tidak seorang pun ingin dicap "lolobangko" atau perawan tua atau yang lebih menakutkan lagi menyandang predikat gadis seumur hidup.

Untuk itu, pembenahan diri dengan berusaha tampil paripurna kerap dilakukan. Bagi perempuan masa kini, spa dengan 
rangkaian perawatannya mungkin telah menjadi menu wajib. Sementara itu, bagi sebagian dara bugis, mereka telah mengantongi warisan leluhur yang diyakini dapat membuat penampilan lebih menarik dalam keseharian. Resep mujarab itu bernama "Cenning rara". Dalam sejarahnya, Cenning rara adalah prosesi untuk mengeluarkan aura dari dalam diri, sehingga telah menjadi sebuah kepercayaan bahwa dengan menggunakan Cenning rara akan mendatangkan jodoh lebih mudah.

Cenning rara sendiri berasal dari kata cenning yang berarti manis dan cendra atau cendrara yang berarti bulan atau matahari yang pada hakekatnya adalah cahaya. Apalagi bulan dalam konteks kebudayaan Bugis merupakan puncak keindahan alam dan di alam. Maka, manis dari keduanya tak lain dimaksudkan untuk membuat diri dan penampilan kian bercahaya seperti bulan atau matahari bagi anak perawan. Cenning rara ini biasa dilakukan dengan media minyak kelapa yang ditanak, telur yang direbus, atau beras yang dijadikan bedak. Dalam perjalanannya, Cenning rara pun terkoptasi oleh nilai-nilai religi yang berkembang di masyarakat. Kuatnya pengaruh islam, menuai perubahan dalam dalam pengadaan media dan mantranya.

\section{PEMBAHASAN}

\section{Hubungan Budaya dengan Bahasa}

Antropolingistik lebih menitikberatkan pada hubungan antara bahasa dan kebudayaan didalam suatu masyarakat seperti peranan bahasa di dalam mempelajari bagaimana hubungan keluarga diekspresikan dalam terminologi budaya.
Dalam ilmu ini di sebutkan bahwa antara bahasa dan kebudayaan mempunyai keterkaitan yang amat erat. Keterkaitan tersebut menurut para ahli adalah bahwa bahasa sebagai alat atau sarana kebudayaan, bahasa sebagai bagian kebudayaan, bahasa merupakan hasil kebudayaan, bahasa hanya mempunyai makna dalam latar kebudayaan yang menjadi wadah nya.

Bahasa juga dijadikan sebagai salah satu persyaratan budaya, yang dalam hal ini di artikan dalam dua hal yaitu:

1. Bahwa bahasa merupakan persyaratan budaya secara diakronis karena kita mempelajari kebudayaan melalui bahasa.

2. Bahasa merupakan persyaratan kebudayaan karena materi atau bahan pembentuk bahasa sama jenisnya dengan materi atau bahan pembentuk keseluruhan budaya yakni relasi logis, oposisi, korelasi dan sebagainya.

\section{Definisi Cenning Rara}

Baca-baca atau dalam bahasa Bugis dan Makassar disebut doang/ paddoangngang. Istilah doang ini kerap merujuk kepada doa yang digunakan untuk suatu tujuan tertentu yang biasanya disertai dengan syarat dan gerakan-gerakan tertentu pula, dengan menggunakan bahasa Bugis atau bahasa Makassar, bahasa Arab, atau gabungan keduanya.

Pada kebudayaan Sulawesi selatan, warisan pappaseng dalam bentuk mantra atau doa-doa (baca-baca) digunakan dengan tujuan berbeda-beda. Cenning rara, misalnya, yang dalam khasanah kebudayaan masyarakat Bugis dan Makassar ditempatkan sebagai mantra pemikat lawan jenis. 
Kata Cenning rara biasa diartikan oleh masyarakat Sulawesi selatan sebagai “wajah manis". Kata 'cenning' memiliki arti manis dimana dalam pengertian masyarakat Bugis, yaitu wajah yang terlihat manis dan menarik. Do'a yang digunakan tentu memiliki makna yang terkait pada hubungan cinta dan kasih sayang.

Bacaan mantra Cenning rara diwariskan oleh leluhur orang Bugis dan Makassar. Meski begitu, kekuatan mantra Cenning rara bisa berbeda-beda pada tiap orang, baik pengguna maupun objek/sasaran mantranya. Sebabnya, cara kerja mantra yang hendak masuk pada ranah psikis seseorang, jiwa mengenalinya sebagai getaran asing. Maka, yang dilakukan psikis seseorang pun sama dengan tubuh. Yakni menolak dan melawannya.

Jika psikis seseorang kuat, pengaruh mantra dapat ditolak untuk kemudian digagalkan. Namun, jika psikis orang itu lemah, akan terjadi hal sebaliknya, ia akan menerima tujuan mantra Cenning rara.

Lebih jauh, mantra Cenning rara akan bekerja jika lima unsur material (jasmani) dan metafisik penggerak cinta yang dimiliki manusia, tepat mengena unsur dominan dalam jiwa. Sebab setiap orang memiliki nilai dominan di antara unsur watak; unsur naluri, unsur rasio, unsur nafsu, dan unsur emosi. Salah satu unsur yang sangat dominan itulah yang pada akhirnya akan menentukan berpengaruh.

Cenning rara dalam secara harfiah bisa juga diartikan Cenning berarti Manis. Rara berarti darah yang identik dengan anak gadis (anak dara). Jadi Cenning rara adalah pemikat yang ditujukan kepada gadis. Cenning rara memiliki teks bacaan (baca-baca/mantra) dan gerakan. Jadi Cenning rara adalah sejenis ilmu pengasihan.

Cenning rara digunakan oleh pria, apabila ia sangat menyukai seorang gadis namun cintanya ditolak. Apalagi jika dipermalukan oleh sang gadis.

Cenning rara dilakukan saat berpakaian dan berdandan. Mulai saat meminyaki rambut dengan minyak kelapa. Pada saat dilakukan, maka teks mantranya dibacakan. Saat menggunakan bedak, teks mantra berbeda kembali dibacakan. Saat menggunakan baju dan celana pun demikian. Juga saat bercermin keluar rumah.

\section{Prinsip Kerja Cenning Rara sebagai Mantra dan Doa}

Mantra adalah ucapan atau lafal yang dianggap mengandung kekuatan ghaib, sering digunakan oleh dukun untuk mengobati pasiennya yang sakit, atau membuat celaka orang lain (Hamid, Syamsuddin:144) . Mantra itu asalnya dari ajaran Hindu tetapi mempunyai pengaruh terhadap umat Islam di Indonesia yang semula memang penganut Hindu, sebelum datangnya Islam. Pengaruhnya bukan hanya pada jaman dahulu saja, tetapi juga bisa disaksikan terus berlangsung sampai sekarang.

Mantra menurut KBBI, yaitu perkataan atau ucapan yang memiliki kekuatan gaib; susunan kata berunsur puisi (seperti rima, irama) yang dianggap mengandung kekuatan gaib, biasanya diucapkan oleh dukun atau pawang untuk menandingi kekuatan gaib yg lain. Adapun Cenning rara termasuk ke dalam jenis mantra pitanggang, yaitu mantra yang menyebabkan perempuan tidak suka 
kepada pria atau tidak menikah seumur hidup karena tidak ada laki-laki yg mencintainya.

Ada umat Islam yang memilih mantra sebagai do'a dengan tujuan khusus dan aneh, misalnya ingin bisa terbang atau menghilang (Ilmu Halimun). Terlebih mantra ilmu asihan (Pemikat Cinta/Pelet), ilmu yang disebut daun cinta ini banyak peminatnya, terutama kalangan muda. Mereka menganggap dengan dengan ilmu tersebut orang menjadi terpikat atau tergila-gila

Bagaimana mungkin sebuah teks mampu mempengaruhi jiwa seseorang? Untuk menjawab pertanyaan itu, kita mesti memahami tentang manusia terlebih dahulu. Bahwa manusia adalah makhluk material (jasmani) dan metafisik.

Mungkin kita semua pernah mengalami sebuah kondisi. Dimana kita baru bertemu dengan seseorang, namun rasanya sangat dekat. Bila berjauhan, selalu nyaman mengingatnya. Atau kondisi kedua, dimana kita telah lama kenal dengan seseorang, namun kita tidak merasa nyaman bila bertemu dengannya.

Kondisi pertama menunjukkan bahwa secara metafisik, kita dekat dengan orang tersebut. Sehingga meski baru pertama kenal rasanya sudah seperti lama kenalan. Atau meski berjauhan, selalu mengingatnya secara nyaman.

Kondisi kedua menunjukkan bahwa secara fisik kita dengan dengan orang tersebut, namun jauh secara metafisik. Sehingga meski bertemu dan berdekatan tempat duduk, rasanya tidak nyaman bahkan mungkin sampai pada titik memusuhinya.

Ilmu pengasihan, termasuk Cenning rarabekerja dengan cara "mendekatkan jiwa pengguna dengan targetnya" sehingga sang gadis yang tidak suka atau tidak tertarik pada sang perjaka menjadi suka dan tertarik sehingga membalas cintanya.

Kembali ke pertanyaan awal, lantas bagaimana dengan teks. Teks sesungguhnya adalah susunan/rangkaian huruf yang merepresentasi makna. Bila teks dirangkai membentuk kalimat yang berisi narasi tentang hajat. Sehingga bila dibaca dengan baik maka akan mempengaruhi jiwa sang pembaca yang pada gilirannya akan mempengaruhi jiwa yang target yang dimaksud.

Bacaan/mantra seiring dengan perbuatan $($ ada $=$ teks) dan (gau = konteks). Dengan demikian akan memaksimalkan penghayatan terhadap teks tersebut.

\section{Hal yang mempengaruhi Efek Cenning Rara}

Bisa jadi seseorang menggunakan Cenning rara dan berhasil, namun pada orang lain justru tidak berhasil. Padahal mantra sama. Berikut ini hal hal yang mempengaruhi keberhasilan efek Cenning rara (tentu pada variabel manusianya).

\section{Keyakinan}

Tujuan apapun yang hendak dicapai pada kondisi tidak yakin mencapainya, akan mengurangi bahkan menggagalkan usaha. Keyakinan juga berarti mensugesti diri agar bisa mencapai tujuan.

\section{Transfer}

Saat sang guru mengajarkan ke muridnya (terutama Cenning rara) bukan hanya teks dan gerakan yang diajarkan. Akan tetapi ditransfer "berkahnya" sebagai kunci untuk mengaktivasi Cenning rara tersebut. Transfer bisa melalui tatapan 
mata, sentuhan tangan guru ke murid, atau gelombang suara tanpa murid sadari. Sehingga wajar misalnya si A mendapatkan Cenning rara dari neneknya (ditransfer tanpa disadari) dan ampuh untuk dirinya. Namun saat temannya yaitu si B mendapati catatan teks mantra Cenning rara (tidak ditransfer) kemudian membaca dan melakukan Cenning rara tapi tidak aktif atau tetap ditolak oleh pujaan hatinya.

\section{Kondisi Sang Gadis}

Berhubung ilmu pengasihan terutama Cenning rara bekerja diwilayah metafisik manusia, maka tentu variabel yang mempengaruhi adalah kondisi si gadis sebagai target ini. Jika jiwanya lemah, maka akan mudah bagi Cenning rara untuk bekerja. Tapi jika jiwa sang gadis kuat. Bisa jadi karena tempaan hidupnya. Bisa jadi karena konsistensi ibadahnya. Bisa jadi karena doa orang orang terdekatnya yang makbul dan seterusnya. Sehingga Cenning rara ini tidak mempan baginya

\section{Usaha}

Gerakan yang dilakukan saat membaca teks mantra Cenning rara (meminyaki rambut, bercermin, memasang baju dan seterusnya) adalah usaha-usaha atau gerakan yang mensinergiskan dengan teks mantra tersebut.

Saat seorang jejaka memasang Cenning raranya tentu ia harus berusaha mendekat pada sang pujaan hatinya. Seperti halnya seseorang yang cuma mengirim sms kata kata cinta tapi tidak melakukan pertemuan langsung, tentu "mantra cinta" yang terkirim lewat sms akan tak berarti

\section{Contoh Mantra Cenning Rara}

Berikut petikan mantra yang biasa diapaki atau dibaca dengan menggunakan bedak. Bacaan ini diajikan sesaat sebelum bedak tersebut dipakai atau disapukan keseluruh permukaan wajah. Berikut kutipannya:

Bedda'na Fatimah u Wabedda,

U paenre ri rupakku

Namatappa pada uleng tepu

Barakka La Ilaha Illallah

Artinya:

Bedaknya Fatimah yang kupakai

Kupakai diwajahku

Dan bercahaya seperti bulan purnama

Semoga allah mengabulkan

Selain menggunakan bedak, sering pula menggunakan media air saat akan mandi atau akan membasuh muka, tujuannya agar si gadis dapat terlihat cantik, berikut kutipannya:

Uwwae pole Mekkah

Jenne' pole suruga

Upatoppoang ri rupaku

Mattappa keteng seppuloeppa

Artinya:

Air dari Mekkah

Air wudhu dari surga

Kubasuh di mukaku

Secerah bulan purnama

Adapun mantra atau baca-baca yang dianggap ampuh oleh masyarakat Bugis dalam memikat pria yang diinginkan sebagai berikut:

oooo anging, laoko muollirengnga la.... (menyebut nama pra yang diinginkan) narekko mupolei matinro paotorengngga' narekko moto'ni patudangekka' narekko tudanni patettongekka' narekko tettonni pajokkangekka lao mai iyapa 
namanyameng nyawana nerekko iya naita kunfayakun barakka' Lailaha Illalah.

artinya:

oh angin, pergilah engkau memanggilkan si ....(menyebut nama pria yang diinginkan) jika engkau temui dia sedang tertidur, bangunkanlah jika telah bangun, dudukkanlah jika telah duduk, berdirikanlah jika telah berdiri, jalankanlah ia kemari barulah perasaannya akan nyaman jika dia melihatku kunfayakun , semua ini berkat Lailaha Illalah.

\section{Mantra yang Sering digunakan oleh Pemuda Bugis}

1. Mantra agar gadis yang disukai merasa senang dan simpati

"Minya'-minya'na to joloku' amminya', ku enre ku tudang ri matanna essoe, matanna essoe matanna yanu lanu ku iyya". Artinya kurang lebih begini : " minyak wanginya leluhurku yang kupakai, saya naik duduk di matahari,matahari, matanya si anu \& si anu sama saya”.

syaratnya ialah, sebelum mantra di ucapkan, terlebih dahulu siapkan minyak rambut atau minyak wangi. oleskan di telapak tangan, lalu ucapkan mantranya dengan keyakinan, kemudian tiupkan ke minyak tadi, lalu usapkan di rambut atau di kening.

2. Mantra Pattiro Ati ( penerawang hati)

" Massuro, usuro, nalettuki suro. Issengengnga melona ( nama) ku iyya. Ku meloi pakkarawa riasekengnga, ku teai pakkarawa riyawangengnga". Artinya " yang mengutus,yang diutus,yang diutuskan. Beri tahu rasa sukanya ( nama) kepada saya. Kalau dia suka, dia memegang ke atas. Kalau dia tidak suka, dia memegang ke bawah”.
3. Mantra untuk Mendapatkan Gadis yang disukai

Setelah tanda didapatkan, barulah para pemuda berusaha mendapatkan gadisnya dengan mantra pengasihan khusus. ada yang melalui pandangan mata, asap rokok, senyuman, sentuhan, mimpi, dan sebagainya.

Contoh mantra melalui pandangan mata: " $i$ nani ri matammu" $3 x$. atau " duppa mata iru mata, iru maddupa ri mata" $3 x$.

Contoh mantra melalui sentuhan "puakku seuwae, barumpunna tana gowa, pakkasilampana tana menre', iyyapa na" $3 x$.

Contoh mantra melaui senyuman " miccu putena uwala” $3 x$.

Contoh mantra melalui mimpi dan ini yang paling keras "purani usio tubummu upattama ri tubukku, purani usio atimmu upatttama ri atikku” $3 x$.

\section{Mantra Cenning Rara menurut Pandangan Islam}

Salafus Saleh yang merupakan ulama Islam mengemukakan bahwa Umat Islam tidak seharusnya menggunakan mantra sebagai doa, sebab mantra adalah bacaan yang dilarang Islam, sementara pelakunya termasuk Syirik, sebagaimana sabda nabi:

1. Agama Islam sudah sempurna. الْيَوْمَ نِعْمَتِي عَلَيْكُمْ وَأَتَمَمْتُ دِينَكُمْ لَكُمْ أَكْمَلْتُ "Pada hari ini telah Kusenpurnakan bagi kalian agama kalian dan telah Kucukupkan nikmatKu kepada kalian dan telah Kurhidhoi Islam sebagai agama bagi kalian.” (QS. Al-Maidah: 3). Ibnu Katsir berkata, "Ini adalah karunia Allah -Ta'ala- yang paling besar terhadap umat ini, di saat Allah telah menyempurnakan agama 
bagi mereka, maka mereka pun tidak butuh lagi kepada agama yang lain dan tidak kepada nabi yang lain selain Nabi mereka -Shollallahu 'alaihi wasallam-. Oleh karena itu, Allah menjadikan beliau sebagai penutup para nabi. Dia telah mengutus beliau kepada bangsa manusia dan jin. Jadi, tidak ada perkara yang halal, selain yang beliau halalkan dan tidak ada perkara yang haram selain yang dia haramkan, serta tidak ada ajaran agama selain yang dia syariatkan.[1].

2. Ikutilah apa yang sudah dijelaskan Sبقِيَ مَا ; Syari'ah. Nabi -Saw. bersabda

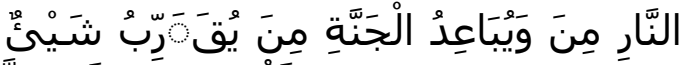
Thiada suatu perkara yang mendekatkan kepada surga dan menjauhkan dari neraka melainkan telah dijelaskan kepada kalian." [2]. Jadi, segala perkara kebaikan yang bisa mengantarkan seseorang meraih surga telah dijelaskan dan dituntunkan dalam syari'at. Demikian pula sebaliknya, segala perkara yang jelek bila menjerumuskan seseorang ke dalam neraka, telah dijelaskan dalam syari'at. Seandainya jimat ini adalah perkara disyari'atkan, tentunya kita akan mendapatkan tuntunannya dalam syari'at dan pastilah Rasulullah Shollallahu 'alaihi wasallam-, para sahabat -radhiyallahu 'anhum-, dan imam-imam setelahnya adalah orang yang pertama kali mengejakannya. Namun, jika kita tidak dapatkan hal tersebut dikerjakan oleh mereka, maka hal tersebut bukanlah perkara yang baik, bahkan termasuk kepada hal-hal yang diada-adakan di dalam syari'at yang telah sempurna ini, yang Allah Subhanahu wa Ta'ala- dan Rasul-Nya berlepas diri dari hal-hal tersebut.
3. Hadits Larangan Menggunakan Jimat, jampi, dan guna-guna. Dari Ibnu Mas'ud r.a., Rasulullah saw. mangisyaratkan tentang jimat dan hukumnya, وَالتِّولَةَ وَالتَمَائِمَ الرُقَى إِنَّ "Sesungguhnya jampi-jampi, jimat-jimat, dan guna-guna adalah syirik." [3].Syaikh Muhammad AlWushobiy Al-Yamaniy berkata dalam mengomentari hadits ini, "Bisa dipetik hukum dari hadits ini tentang haramnya menggantungkan jimat, baik pada manusia, hewan, kendaraan, rumah, toko, pohon, atau selainnya. Apakah sesuatu yang dgantungkan itu berupa tulang, tanduk, sandal, rambut, benangbenang, batu-batu, besi, kuningan, atau yang lainnya, karena perkara tersebut, di dalamnya ada bentuk penyandaran sesuatu kepada selain Allah, (yang ia itu adalah kesyirikan )". [4]. Nabi Shollallahu 'alaihi wasallam- juga pernah bersabda, فَقَدْ تمَيْمَةً عَلَّقَ مَنْ فَّْْ تمر 'Siapa yang menggantungkan jimat maka sungguh dia telah berbuat kesyirikan." [5].

\section{PENUTUP}

Cenning rara adalah salah satu contoh baca-baca yang terkenal dikalangan masyarakat Bugis Makassar. Dimana bacabaca Cenning rara ini banyak digunakan untuk mantra awet muda dan sering juga digunakan untuk memikat lawan jenis. Biasanya ritual Cenning rara ini dibacakan melalui air untuk mandi atau bedak bagi gadis, dan melalui asap rokok bagi pemuda.

Cenning rara terbagi atas dua bahasa, yaitu bahasa bugis dan bahasa makassar. Sering digunakan oleh orang tua dulu dari kalangan laki-laki untuk menaklukkan wanita pujaan hatinya. 
Namun baca-baca Cenning rara tidak hanya sekedar dibaca dan diucapkan, tetapi harus dilengkapi dengan syarat-syarat dan ritual-ritual.

Ilmu pengasihan, termasuk Cenning rarabekerja dengan cara "mendekatkan jiwa pengguna dengan targetnya" sehingga sang gadis yang tidak suka atau tidak tertarik pada sang perjaka menjadi suka dan tertarik sehingga membalas cintanya. Sebenarnya Cenning rara melakukan rekayasa perasaan terhadap sang gadis sehingga ia berubah dari tidak suka/hambar atau benci menjadi suka atau jatuh cinta. Karena merekayasa perasaan orang lain, tentu ini kurang baik. Sebab sama saja memaksa orang lain. Padahal sudah umum orang pahami bahwa dalam dunia percintaan, tak ada paksaan didalamnya.

Ada empat hal yang diyakini dapat memengaruhi efek Cenning rara antaralain; keyakinan sang pengguna, transfer, kondisi orang yang akan dibacaibacai, serta usaha. Bisa jadi seseorang menggunakan Cenning rara dan berhasil, namun pada orang lain justru berhasil. Padahal menggunakan mantra yang sama.

Namun terlepas dari segala tujuannya, Cenning rara dapat dilihat pula menurut pandangan islam, yaitu Umat Islam tidak seharusnya menggunakan mantra sebagai doa, sebab mantra adalah bacaan yang dilarang Islam, sementara pelakunya termasuk Syirik.

\section{DAFTAR RUJUKAN}

Diskusi Lepas. (2014). Prinsip Kerja Mantra Cenning rara, (Online, https://www.diskusilepas.id/)

Dunia Penuh Warna. (2010). Cenning rara, Alternatif Mendapatkan Jodoh? (Online, http://herniamir.blogspot.co.id/)
Gudang Baca. (2016). Bacaan Mantra Pemikat Hati Lawan Jenis Khas Orang Bugis Makassar, (Online, http://anassalehe.blogspot.co.id/)

Hamid, S. (2011). Kumpulan Sarikata Peribahasa Pantun dan Puisi. Jakarta: Gama Press.

Ilmu Sakti. (2016). Mantra Cenning rara dari Bugis, (Online, http://ilmusakti.com/)

Koentjaraningrat. (2015). Pengatar Ilmu Antropologi. Jakarta: Rineka Cipta.

Mansyur, U. (2016a). Bahasa Indonesia dalam Belitan Media Sosial: Dari Cabe-Cabean Hingga Tafsir AlMaidah 51. In Prosiding Seminar Nasional \& Dialog Kebangsaan dalam Rangka Bulan Bahasa 2016 (pp. 145-155). Fakultas Ilmu Budaya Universitas Hasanuddin. https://doi.org/10.31227/osf.io/7vpjh

Mansyur, U. (2016b). Pemanfaatan Nilai kejujuran dalam Cerpen sebagai Bahan Ajar Berbasis Pendidikan Karakter. In Mengais Karakter dalam Sastra: HISKI Makassar (pp. 330339). https://doi.org/10.17605/OSF.IO/Z4T $3 \mathrm{Y}$

Mansyur, U. (2018). Kiat dan Teknik Penulisan Skripsi bagi Mahasiswa. INA-Rxiv. https://doi.org/10.31227/osf.io/juds7

Ruqyah, M.S. (2014). Ilmu "Baca-Baca" dari Bugis Makassar (Online, http://simplelinx.blogspot.co.id/)

Yusuf. (2013). Cenning rara Orang Bugis? (Online, http://yusufbloggerpinrang.blogspot.c o.id/) 